\title{
MONITOR - AN INFORMATION SYSTEM FOR IMPROVED MUNICIPAL ENVIRONMENTAL MANAGEMENT
}

\author{
Frostell, $B$ \\ Industrial Ecology Royal Institute of Technology (KTH), Sweden
}

\begin{abstract}
MONITOR is a joint research effort between a number of research institutions and the city of Stockholm. It aims at developing an environmental information system based on (i) accountings of flows and stocks of materials and energy (environmental pressure) as well as describing the (ii) state of the environment and the (iii) environmental impact in an integrated way. In MONITOR, data from existing environmental monitoring in Stockholm is integrated with new information on material flows and stocks. A first prototype, illustrating the potential benefits of MONITOR has been developed. A long-term goal is to develop a tool for an improved economising of materials and energy in the Stockholm region. In the paper, the MONITOR programme is presented as well as initial practical approaches to the work.
\end{abstract}

\section{KEY WORDS}

Environmental monitoring; environmental information system; material flows; Material Flow Accounting: municipal environmental management.

\section{INTRODUCTION}

The further development of metropolitan regions in harmony with requirements for a sustainable development is a formidable and important task. Metropolitan regions will presumably grow in population during the next few decades. This necessitates that new ground and water areas will be used for urbanisation. At the same time, the gradual adaptation of the current metropolitan life and service functions to a more sustainable route needs much effort. All this will require improved methods for forecasting and surveying the development of environmental issues in metropolitan areas including the assessment and evaluation of various alternatives for action and development.

Many countries have gradually introduced monitoring systems for urban environmental quality and immissions to the environment. In parallel, infiormation on emissions from point sources has been obtained from different emission control systems. Information thus gathered - especially from air and water monitoring - has influenced policy development and the 
implementation of a number of environmental measures with emphasis on point sources. Of increasing concern is therefore non-point source pollution. A strong current challenge is to identify and control non-point source pollution, which necessitates new approaches in environmental monitoring and emission control. The situation represents a serious problem not only in Stockholm, but also in many other regions of the world, e.g. Europe (cf. Bayliss \& Walker, 1994).

There is, however, another important problem with respect to local environmental management in Sweden. Investigations have shown that environmental monitoring procedures have little influence on the overall decision - making process regarding environment and development issues in Swedish municipalities (Brandt \& Frostell, 1995; Brandt et al, 1999). This was the case both for setting environmental goals and for the environmental management on a whole. A severe shortcoming of present local environmental monitoring (or information collection) in Sweden is the lack of systems approach (Brandt et al, 1999). To a great extent. information on different sources, flows and sinks of important materials in society are lacking.

This implies that (environmental) management of Cities needs to be improved in the future, due to an increasing need to understand the metabolism of Cities and municipalities. The supply of relevant information as a basis for decisions is of utmost importance in such an improved environmental management loop for Cities (cf. Figure 1).

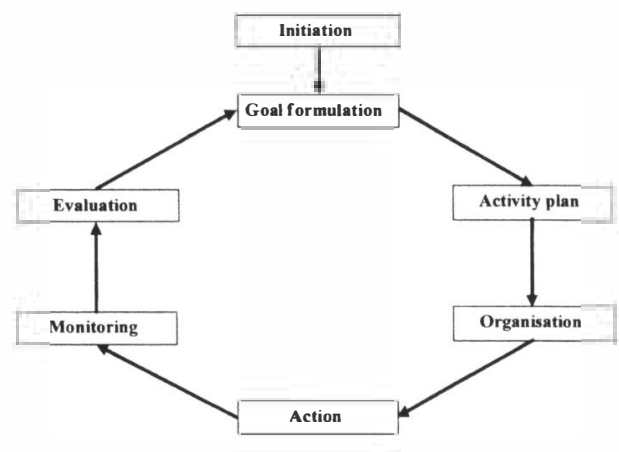

Fig. 1 The (environmental) management loop.

The approach to local environmental monitoring thus needs to be changed. The qualitative and quantitative knowledge of different natural and anthropogenic material flows needs to be improved. A more system-oriented approach needs to be taken. In principle, knowledge of all existing natural and anthropogenic material flows have to be established. In the ecologically sustainable city, thereafter, the material flows have to be kept within limits set by the overall assimilating capacity of the local, regional and global eco-systems. The elaborated information of flows must be connected to the qualitative and quantitative knowledge of state and impact. This integrated information will form the prerequisite for the implementation of different measures. 
In order to implement the ideas behind Agenda 21, the local citizen must be stimulated to take an active part in the work towards sustainable development. An important aspect of introducing improved environmental monitoring and information systems therefore is to present results in a pedagogic and sometimes simplified way. It must be possible for different actors, such as the public, administrators, engineers, planners and politicians to understand the message without great effort. Getting the message through is a key question.

MONITOR was started with the aim to develop a more systems oriented approach to environmental monitoring and information generation. The basic ideas behind MONITOR have been described by Frostell et al (1998).

\section{APPROACH AND ORGANISATION OF WORK}

In discussing environmental problems, their causes, impacts and potential responses, reference is often made to the so-called PSR (cf. OECD 1993) and the more extended DPSIR (cf. EEA, 1998) models for environmental management. Both the PSR and the DPSIR models are based on the fact that different social activities (drivers) cause a pressure on the environment, causing quantitative and qualitative changes of it (changing state and impact). Society has to react (respond) to these changes in order to achieve a sustainable development. By use of the PSR (DPSIR) model, different indicators of sustainability may be established, covering all aspects of the model (drivers, pressure, state, impact and response). The DPSIR model is schematically outlined in Figure 2.

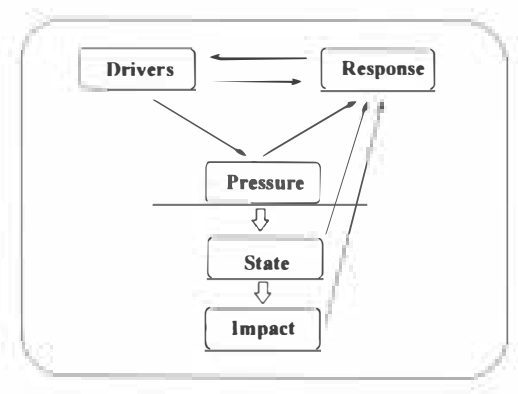

Figure 2. A revised schematic drawing of the DPSIR model to illustrate the relations between social drivers, environmental pressure, state and impact and finally responses to improve the situation. The model emphasises the importance of information collection from the different parts of the physical social system. 
To meet increasing information demands, MONITOR has been conceptually modelled to include both pressure, state and impact information (cf. Figure 3).
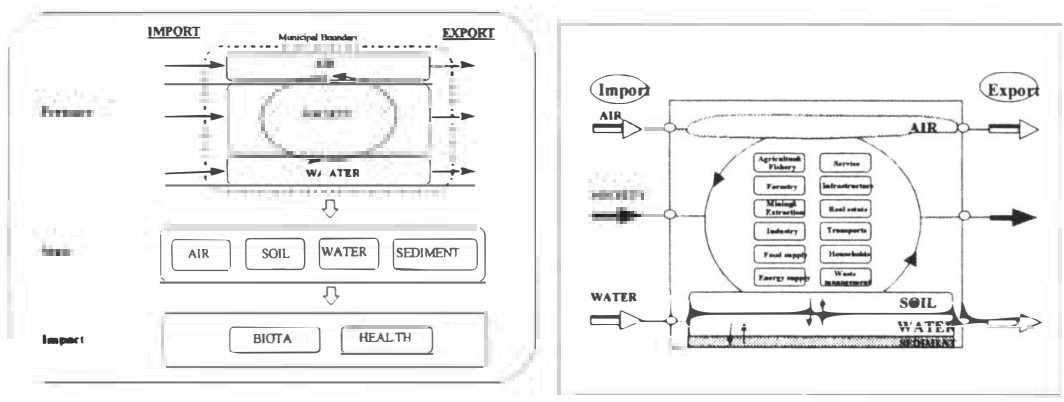

Figurc 3 ('onceptual model of the MONITOR environmental information system (a) and its environmental pressure part the ComBox model (b).

The pressure part is based on ideas developed by Frostell et al, 1994) and further developed into the so-called ComBox model (Frostell, et al, 1999).

The suh-system society is in turn divided into 12 different social sectors (Burström, 1996; cf. Figure 3b).

For the pressure part, several investigations have been performed according to the ComBox model until spring 1999. They are nitrogen in the Varberg municipality (Burström, 1996), Nitrogen and Phosphorus in the city of Stockholm (Burström et al, 1998), Cadmium in the city of Stockholm (Hannerz, 1998), Nitrogen in the city of Västerås (Andersson, 1998) and Polycyclic Aromatic Hydrocarbons (PAH) in the city of Stockholm (Bevilacqua, 1999).

MONITOR is operated as a joint project between the following institutions:

- Industrial Ecology, KTH, Stockholm

- Dep. of Civil and Environmental Engineering, KTH, Stockholm

- Institute of Applied Environmental Research, Stockholm University, Stockholm

- Swedish Environmental Research Institute, Stockholm, Sweden

- Dep. of Physical Geography, Stockholm University, Sweden

- Environment and Health Protection Administration of Stockholm

A Board manages the project with representation from the six research groups and the city. Chairman is a representative from the city. Project work is carried out in 5 different subprojects, (i) Air, (ii) Water, (iii) Society, (iv) Informatics and (v) Biota. 


\section{RESULTS}

During 1998, the MONITOR work has been focused on developing a prototype for the MONITOR approach. The prototype is based on the flows and stocks of Polycyclic Aromatic Hydrocarbons $(\mathrm{PAH})$ in Stockholm. In the prototype, all available information on PAH in Stockholm was collected and presented according to the MONITOR format comprising

- General information on PAH and the risks with them.

- Charts and flows according to the ComBox model at three different detail levels:

$>$ Imports and exports through the air water and society sub-systems,

$>$ an overall flow-chart showing the flows and stocks in 17 different sub-sectors,

$>$ flow-charts for each individual sector.

- GIS-based maps of concentrations of PAH in different parts of the city

A number of important PAH flows in the city of Stockholm, estimated according to the ComBox model within the MONITOR project, are shown in Figure 4. In the Figure, also PAHs with 2 rings have been included. This is the reason why the imports to the energy and transport sectors were of such a large magnitude.

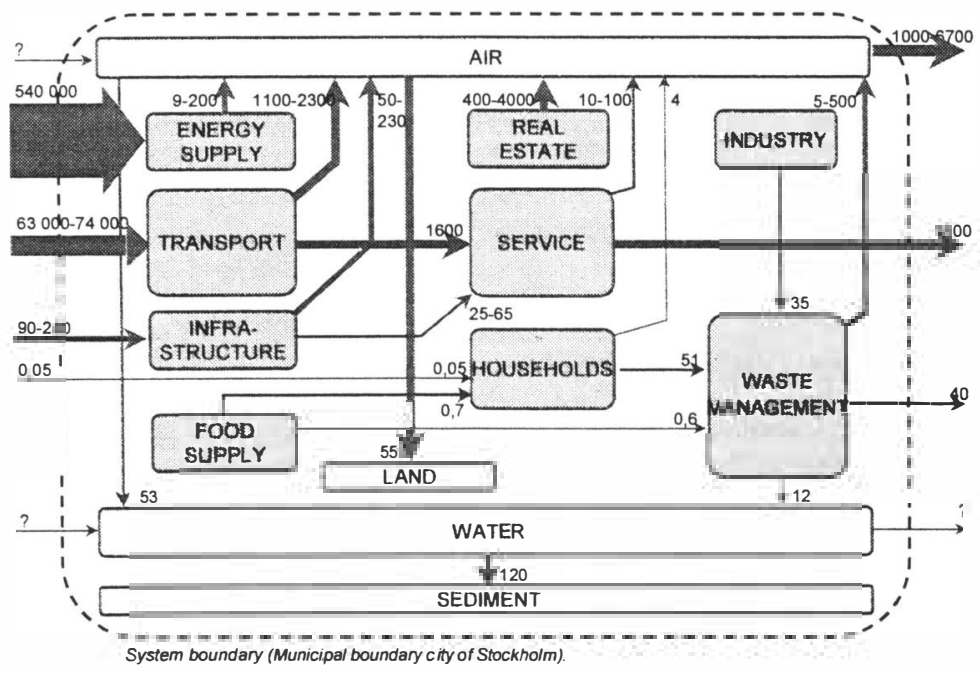

Figure 4. An estimate of some important PAH flows (kg/yr) in the city of

Stockholm 1995 (Bevilacqua, 1999). 


\section{DISCUSSION}

The MONITOR project is in many aspects different from traditional research projects in the environmental field. Among differences are:

$>$ It has the aim to establish a comprehensive metabolic picture of the entire city system of Stockholm and thus is very broad in scope.

$>$ It involves six research groups with very different backgrounds and basic activities.

$>$ It has the city of Stockholm directly involved in the work.

In practice, the research task cannot be said to fit into any existing research funding structure or established work structure. The project has seen difficulties in finding appropriate financing for the size of the task. It has also become clear that a long time is necessary to establish a common intellectual platform in the large project group, where normally 15-20 persons gather for 1-2 day meetings and workshops. Nevertheless, the project has seen substantial progress already in its first year and the city of Stockholm in June 1999 officially declared the following: 'Monitor's interdisciplinary approach gives light to important issues and has several good characteristics such as professionalism, international networks, and an aim to improve the long term environmental work of the city..."

According to the EHPAS of Stockholm, MONITOR may already now contribute to an improvement of the city environmental management with the following:

- To make priorities between different measures from a legal perspective,

- to improve the environmental management system of the city,

- to strengthen the message in different programmes, plans and policy acts,

- to support the planning work of the city,

- in the granting of ground exploration permit,

- in different procurement procedures,

- In the Agenda 21 work.

\section{ACKOWLEDGEMENTS}

Many people have contributed to the MONITOR project. I would especially like to acknowledge the following persons: Ulf Mohlander, Mathias Cramér and Urban Jonsson from the city of Stockholm; Dag Broman, Hans Christen Hansson, Anna Holmgren, Christer Johansson, Roger Westerholm and Leif Wastenson from the Stockholm University, Sam Ekstrand, Mikael Olshammar and Christian Hansen from the Swedish Environmental Research Institute, Fredrik Burström, Monica Dahlqvist and Thomas Larm from the Royal Institute of Technology. Financial support from mainly the city of Stockholm and from the Swedish EPA as well as Stockholm University and The Royal Institute of Technology is gratefully acknowledged. 


\section{REFERENCES}

Andersson, J. (1998) Datorbaserad redovisning av kommunala materialflöden: Kväveflöden $i$ Västerås kommun 1995, M. Sc. Thesis, Royal Institute of Technology, Dept. of Chemical Engineering, Div. of Industrial Ecology, Stockholm (in Swedish).

Bayliss, D. \& Walker, G. (1994) Environmental monitoring in the European Union, European Environment, 4, pp.14-17.

Bevilacqua, C. (1999) PAHs in the city of Stockholm 1995, M. Sc. Thesis, Royal Institute of Technology, Dept. of Chemical Engineering, Div. of Industrial Ecology, Stockholm.

Brandt, N. and B. Frostell (1995) Environmental Monitoring at the Local Community Level in Sweden 1994 - An Attempt to a Systems Approach, IVL-Report B 1173. Swedish Environmental Research Institute. Stockholm (In Swedish with English Summary).

Brandt, N., B. Frostell, S. Ekstrand and K. Hallding (1995) The Community Box - A Systematic Approach to Environmental Monitoring, IVL-Report B 1178. Swedish Environmental Research Institute. Stockholm (In Swedish).

Brandt, N., Frostell, B. \& Burström, F. (1999): Local Environmental Monitoring in Sweden: the need for a new Strategy?, Local Environment, Vol. 4, No. 2, 181-193.

Burström, F. (1996) Material flow analysis as a tool in environmental monitoring at the local level - Nitrogen flows in the municipality of Varberg 1994, M. Sc. Thesis, Royal Institute of Technology, Dept. of Environmental Technology and Work Science. Stockholm (In Swedish).

Burström, F., N. Brandt and B. Frostell (1997) Local Environmental Monitoring in the City of Stockholm, TRITA-IMA Report 1997:1. Royal Institute of Technology, Dept. of Environmental Technology and Work Science. Stockholm (In Swedish).

Burström, F., Brandt, N., Frostell, B. \& Mohlander, U. (1997) Material flow accounting and information for environmental policies in the city of Stockholm, Paper presented at the ConAccount Conference, "From Analysis to Action", September 11-12, 1997, Wuppertal, Germany.

EEA (1998): Europe's Environment - The $2^{\text {nd }}$ Assessment, European Environment Agency, Office for Publications of the European Communities, ISBN 92-828-3351-8.

Frostell, B., Hallding, K., Ekstrand, S. \& Brandt, N. (1994): Integrated Environmental Monitoring at the Municipality Level - A Conceptual Approach, IVL-Report B 1157, Stockholm (In Swedish with English Summary).

Frostell, B., Brandt, N. \& Burström, F. (1999) The ComBox Model - An Approach to Material Flow Accounting in the local Community (manuscript).

Frostell, B., Broman, D., Cramér, M., Ekstrand, S., Freland, M., Hansson, H.-C., Jonsson, U., Mohlander, U. and Wastenson, L. (1999) MONITOR - an integrated environmental information system, Proc. ConAccount Workshop on Ecologizing Societal Metabolism - Designing Scenarios for Sustainable Materials Management, November $21^{\text {st }} 1998$ Amsterdam, The Netherlands, CML report 148, Leiden University.

Hannerz, N. (1998) Systemorienterad kommunal hantering av kadmium m.h.a. materialflödesanalys, M. Sc. Thesis, Royal Institute of Technology, Dept. of Environmental Technology and Work Science. Stockholm (In Swedish).

OECD (1993): OECD Core Set of Indicators for Environmental Performance Reviews, Environmental Monograph No 83, OECD, Paris. 